Journal of Nursing Care Quality

Issue: Volume 14(1), October 1999, pp 63-71

Copyright: Copyright $\odot 1999$ by Aspen Publishers, Inc.

Public ation Type: [Coordinating The Continuum Of Care]

ISSN: 1057-3631

Accession: 00001786-199910000-00008

Keywords: asthma, continuity of care, nurse clinics, quality of care, transmural care

[Coordinating The Continuum Of Care]

\title{
Dutch Nurse Clinics for Children with Asthma: Views of Professionals and Parents
}

Temmink, D. MN, RN; Hutten, J.B.F. PhD; van der Zee, J. PhD; Huyer Abu-Saad, H. PhD, RN

\section{Author Information}

NIVEL; Netherlands Institute of Primary Health Care (Temmink)

NIVEL; Netherlands Institute of Primary Health Care (Hutten)

Professor; NIVEL; Netherlands Institute of Primary Health Care (van der Zee)

Utrecht, The Netherlands

Professor; Faculty of Health Sciences, Department of Nursing Science; Maastricht University; Maastricht, The Netherlands (Abu-Saad)

\section{Abstract}

In the Netherlands, there are two kinds of nurse clinics for asthmatics. Extramural nurse clinics are run under the sole responsibility of a home care organization while transmural nurse clinics are run under the joint responsibility of a home care organization and a hospital. This article gives insight into the opinions of professionals and parents of asthmatic children about the care given at these clinics. The conclusion is that organizational differences between the clinics do not influence parents' (positive) perceptions about the quality and continuity of care provided at the clinics.

The care of persons with asthma, as with people with other chronic conditions, involves a variety of health care professionals and services in both primary and secondary care settings. 1,2 The quality of asthma care can vary and may result in poor treatment in both hospitals and home care settings. In the first place, asthmatic patients often need more information about their disease and its treatment. Patients and parents of asthmatic children want to know more about possible causes of the disease, the management of worsening conditions, how to decide when to summon medical help, the nature of the drugs and their side effects, and the likely prognosis. 3 Parents of asthmatic children also request information on how to deal with their asthmatic child at school, during holidays, and in everyday life. In the Netherlands, it also appears that health care for asthmatic patients is poor in regard to waiting time at the primary care provider's or lung specialist's office. The coordination of care given by these professionals also is regarded as poor. 4

Foreseeing the problems in the care for asthmatics, nurse-run asthma clinics have been established in the United Kingdom and the Netherlands. 2,5-9 At these clinics, nurses give patients information about topics like inhaler techniques and asthma preventers and relievers. 8,9 In addition, they support patients in how to deal with their asthma in daily life. 9 The organization of Dutch asthma clinics can vary from clinics run under the sole responsibility of a home care organization (so-called extramural nurse clinics) to clinics that are run under the joint responsibility of a home care organization and a hospital (called transmural nurse clinics). Patient and professional demands for good, quality health care are expected from both types of clinic. Transmural nurse clinics also are expected to improve the continuity of care and cooperation between home care and hospital

professionals (for example, community nurses and pediatricians). Whether these expectations actually are met is as yet unknown. Consequently, this article will target specialist nurses' and pediatricians' assessments of transmural and extramural nurse clinics for asthmatic children. The object also is to give insight into the perceptions of the parents of asthmatic children about the quality and continuity of care received at transmura and extramural nurse clinics. The following are research questions addressed in this article: What are specialist asthma nurses' perceptions about transmural and extramural nurse clinics in the Netherlands? What are pediatricians' perceptions about transmural nurse clinics in the Netherlands? Do parents' perceptions about the quality and continuity of care reveal a difference in the assessment of transmural and extramural nurse clinics in the Netherlands?

\section{METHOD}

Sample

The study was conducted at six locations in the Netherlands. At four locations, a home care institution and a hospital collaborated closely and had joint responsibility for a transmural nurse clinic. All transmural nurse clinics were held by asthma community nurses at a hospital outpatient department. Extramural nurse clinics for asthmatic children were held by asthma community nurses at two locations in a building belonging to a home care organization. The home care organization bore the sole responsibility for the clinics.

Four nurses and five pediatricians involved in transmural nurse clinics as well as two nurses heading an extramural nurse clinic were interviewed. 
Parents of asthmatic children participated in the study in addition to professionals. (The term "parent" will be used further to indicate both asthmatic children and their parents.) The following criteria were used for parents and their children in this study: (1) diagnosis of chronic non specific lung diseases [for example, asthma or chronic obstructive pulmonary disease (COPD)], (2) age below 14 years, (3) no previous contact with the nurse specialists (4) one parent who speaks Dutch and (5) telephone access. Parents received a letter with information about the study. Those who chose to participate gave written consent.

Between April 1996 and February 1998, a total of 237 respondents were covered by the study. Of those, 152 attended a transmural nurse clinic while the remaining 85 visited an extramural nurse clinic. Thirteen of the 152 parents visiting a transmural nurse clinic and 22 of the 85 parents visiting an extramural nurse clinic dropped out of the study. This means that information is available about 139 parents visiting a transmural and 63 parents visiting an extramural nurse clinic ( $85 \%$ response).

The respondents visiting the two kinds of clinics were comparable on most of the background characteristics. In both groups, the children had a mean age of five years, 60 percent were male, and the mean duration of the disease was three years. Most of the parents had primary or secondary education and 95 percent were female and had contacted the specialist nurse about twice during the research period of six weeks. A significant difference in the severity of children's asthma was found between the two groups. Children visiting an extramural nurse clinic appeared to have less severe asthma than children visiting a transmural nurse clinic. About half the children $(49 \%)$ had moderate asthma.

\section{Measurement instruments}

For the first research question, semi-structured interviews were held with pediatricians involved in transmural nurse clinics and with specialist asthma nurses involved in transmural and extramural nurse clinics. Leading questions posed in the interviews were: (1) What are positive and negative aspects of the clinic? (2) What are inhibiting factors for running the clinics? and (3) Is it important to continue the clinic in the future? The interviews lasted about 45 minutes and were audio-taped.

Parents were approached for a telephone interview on two occasions. The interviews lasted from about 15 to 30 minutes. The first telephone interview with parents was conducted one to four days before the parent and child visited a nurse clinic (T0) while the second interview took place six weeks after their first visit at the nurse clinic (T1). To examine parents' perceptions of the quality of care, the Quality of Care through the Patient's Eyes for asthma and COPD patients (QUOTE-CNSLD) 4 was used. In the QUOTE-CNSLD, parents at T0 were asked to rate the importance (I) of 16 health care service indicators (for example, "health professionals should be fully conversant with my problems"; response range 1-4). Parents at T1 were asked to rate the perceived performance $(P)$ on each indicator in their perception (for example, "the specialist nurse is fully conversant with my problems"; response range 1-4). The QUOTE-CNSLD has been shown to be a reliable and valid instrument for assessing the quality of health care services from the perspective of non-institutionalized CNSLD patients. 4

To examine parents' perceptions of the continuity of care, the questionnaire on Continuity of care from the Clients' perspective (QCC) 10 was used. Analogous to the QUOTE-CNSLD, in the QCC questionnaire, parents were asked to rate, at T0, the importance (I) and, at T1, the perceived performance ( $\mathrm{P}$ ) of 15 continuity health care service indicators (score range 1-5). The QCC instrument has been shown to be a reliable and valid instrument for assessing the continuity of health care services from the perspective of CNSLD patients. 10 Because of the difference in score range, the importance and performance scores of the QUOTE-CNSLD and QCC are incomparable.

Analyses

The interviews with specialist nurses and pediatricians were analyzed using qualitative analysis techniques. 11,12 The interviews were transcribed and stored in Kwalitan, a computer program for practical support in qualitative analyses. 13 All interview fragments that were related to the first research question were given one or more key words. The interview fragments then were grouped by key word and compared with fragments with the same key words.

The quality and continuity of care in transmural and extramural nurse clinics were defined as "optimal" when parents' experiences with the clinics ( $P$ measured at $T 1$ ) were at least congruent with their individual importance scores (I measured at T0). For each indicator, average importance and performance scores were calculated to determine discrepancies between importance and performance score. Mean ratio scores $(R)$ then were calculated for each indicator by means of dividing perceived performance scores (T1) by importance scores (T0) for every individual patient. Mean ratio scores of 1.0 or higher indicate a positive score on a specific indic ator. Mean ratio scores below 1.0 indicate a negative score on a specific indicator. If, for instance, a parent rated the importance of an indicator with score 3.0 and the performance with 2.0, the ratio score of $0.75(2.0 / 3.0)$ indicates a negative score on that specific indicator.

Differences in ratio scores between parents visiting a transmural or extramural nurse clinic were determined by ANCOVA with statistical adjustment for the baseline difference between the two groups in severity of the illness. 


\section{RESULTS}

Specialist asthma nurses' and pediatricians' perceptions

Both specialist nurses and pediatricians are positive about the clinics involved. The accessibility of the clinics and the time available were experienced as strongly positive. In both types of nurse clinics, nurses have more time with the parents than the time available at a pediatricians' clinic. This gives nurses the option of providing parents with information additional to that given by pediatricians.

One pediatrician stated:"In a medical clinic, the time is limited and it is only possible to provide limited information about illness-related aspects. The specialist nurse has more time during her clinic and can give additional information about, for instance, the inhalation method." According to them, parents discuss some problems (like not knowing how to use the medicines) more easily with a specialist nurse than with a pediatrician. (3-3-1)(These numbers indicate the place of the specific fragment in the Kwalitan program. The first number refers to the work file, the second to the document code, and the third to the scene number.)

In addition, all nurses and three of the five pediatricians interviewed mentioned that the clinic involved resulted in more accessible care. Impeding factors concerning transmural and extramural nurse clinics also were mentioned. In both kinds of clinics, the referral system to the clinics can be improved. For instance, in extramural nurse clinics, patient referrals from general practitioners and pediatricians seem to be made on an incidental rather than a structural basis. In the initial phase at transmural clinics, structured referral was seen as an impediment.

A nurse stated: "Several doctors can refer parents to my clinic. These doctors all have their own views on the care process. This has resulted in differences in referral patterns between doctors. These differences result in differences in the content of the care given, while parents' situations are comparable." (4-2-18).

Parents' perceptions of the quality of care

Table 1 shows the scores on the 16 quality indicators. It appears that parents who visit transmural or extramural nurse clinics (at T0) attach great importance to most of the quality indicators. Parents rated indicator 4, "to be taken seriously by health professionals and institutions," of the highest importance, followed by indicator 8, "tell me what to do when I use other medicines besides the prescribed ones"; 11, "physicians and nurses should know how my inhaler works'; and 15, "wards, waiting rooms and consulting rooms should be entirely smoke-free."

\begin{tabular}{|c|c|c|c|c|c|c|c|}
\hline \multirow[t]{2}{*}{ No. } & \multirow[t]{2}{*}{ Indicator description } & \multicolumn{3}{|c|}{$\begin{array}{c}\text { Parents visiting } \\
\text { a transmural nurse } \\
\text { clinic } \\
(n=139)\end{array}$} & \multicolumn{3}{|c|}{$\begin{array}{c}\text { Parents visiting an } \\
\text { extramural nurse } \\
\text { clinic } \\
(\mathbf{n}=63)\end{array}$} \\
\hline & & $\mathbf{I}$ & $\mathbf{P}$ & $\mathbf{R}^{2}$ & $\mathbf{I}$ & $\mathbf{P}$ & $\mathbf{R}^{2}$ \\
\hline \multicolumn{8}{|c|}{ Health professionals or health institutions should: } \\
\hline 1 & be fully conversant with my problems & 3.5 & 3.7 & 1.1 & 3.3 & 3.7 & 1.1 \\
\hline 2 & work efficiently & 3.4 & 3.9 & 1.2 & 3.3 & 3.9 & 1.2 \\
\hline \multirow[t]{2}{*}{3} & allow me to decide on what & & & & & & \\
\hline & help to get & 2.8 & 3.9 & 1.6 & 2.8 & 4.0 & 1.6 \\
\hline 4 & take me seriously & 3.8 & 3.9 & 1.1 & 3.6 & 4.0 & 1.1 \\
\hline 5 & keep their appointments & 2.8 & 3.7 & 1.5 & 2.8 & 4.0 & 1.6 \\
\hline \multirow[t]{2}{*}{6} & allow me to choose another & & & & & & \\
\hline & professional & 3.3 & 3.5 & 1.0 & 3.2 & 4.0 & 1.1 \\
\hline 7 & $\begin{array}{l}\text { never let me wait in the waiting } \\
\text { room longer than } 15 \text { minutes }\end{array}$ & 2.2 & 3.5 & 2.0 & 2.5 & 3.9 & 1.8 \\
\hline \multirow[t]{2}{*}{8} & $\begin{array}{l}\text { tell me what to do when I use } \\
\text { other medicines besides the }\end{array}$ & & & & & & 1.0 \\
\hline & prescribed ones & 3.6 & 3.6 & 1.0 & 3.5 & 3.8 & 1.1 \\
\hline 9 & be easily accessible by telephone & 3.2 & 3.6 & 1.2 & 3.3 & 3.6 & 1.2 \\
\hline 10 & ensure good coordination & 3.5 & 3.8 & 1.1 & 3.3 & 3.8 & 1.2 \\
\hline \multirow[t]{2}{*}{11} & physicians and nurses should & & & & & & \\
\hline & know how my inhaler works & 3.7 & 4.0 & 1.1 & 3.5 & 4.0 & 1.1 \\
\hline 12 & $\begin{array}{l}\text { health professionals should not } \\
\text { label my physical problems } \\
\text { caused by asthma/COPD as }\end{array}$ & & & & & & \\
\hline 13 & $\begin{array}{l}\text { psychological } \\
\text { health professionals should be }\end{array}$ & 3.4 & 3.9 & 1.2 & 3.2 & 3.9 & 1.4 \\
\hline
\end{tabular}




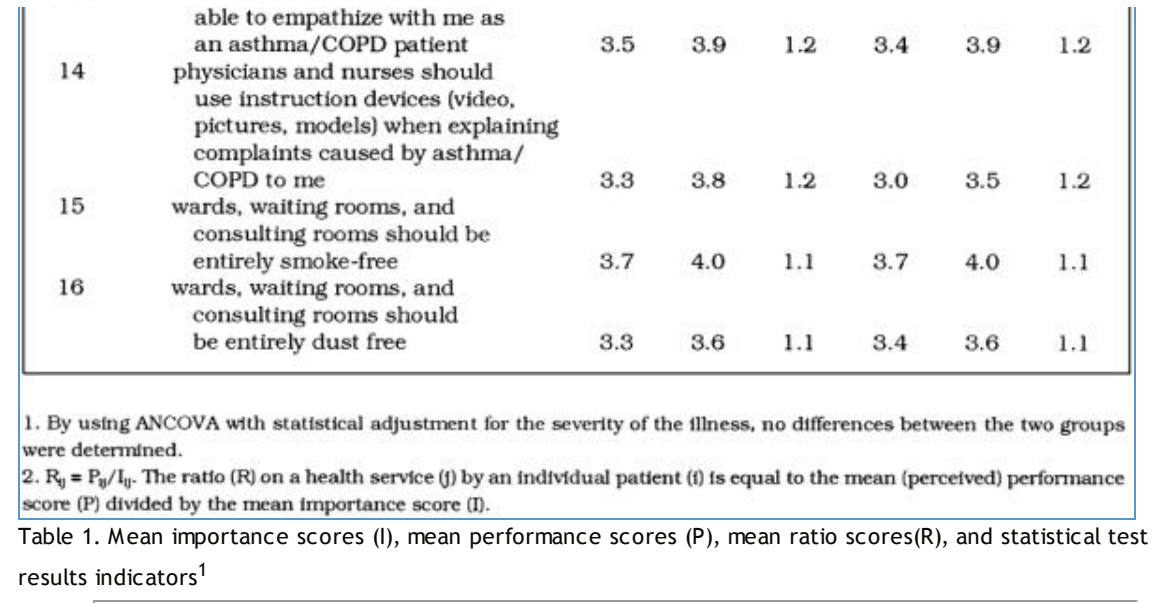

Parents' perceptions $(\mathrm{P})$ of transmural and extramural nurse clinics were optimal in regard to indicator 11, "physicians and nurses should know how my inhaler works," and 15, Owards, waiting rooms and consulting rooms should be entirely smoke-free." The performance score of 4.0 shows that all parents visiting a nurse clinic had an optimal positive judgment on these indicators. Parents also rated the quality of extramural nurse clinics optimal in regard to indicator 3, "allow me to decide on what help to get"; 4, "take me seriously"; 5, "keep their appointments"; and 6, "allow me to choose another professional" (see Table 1).

The optimal quality of care in transmural and extramural nurse clinics also is reflected in the mean ratio scores $(\mathrm{R})$ in Table 1. On all quality indicators, a mean R score of 1.0 or higher appears. This indicates that on all quality of care indicators, parents' perceptions of nurse clinics are positive.

Finally, Table 1 shows that no significant differences were found between transmural and extramural nurse clinics with respect to the quality of care perceived by parents.

Parents' perceptions of the continuity of care

Table 2 displays indicators measuring the continuity of care, mean continuity importance scores (I), mean perceived performance scores $(\mathrm{P})$, and mean ratio scores $(\mathrm{R})$ of the participating parents. It appears that parents who visited a transmural or extramural nurse clinic (T0) attached great importance to almost all continuity indicators. Parents rated the following continuity indicators as being of the greatest importance: 2 , "adapt care when necessary in changing situations"; 3, "provide care immediately during emergencies"; 7, "provide concurrent care"; and 14, "give each other sufficient information concerning patients' situation."

\begin{tabular}{|c|c|c|c|c|c|c|c|}
\hline \multirow[t]{2}{*}{ No. } & \multirow[t]{2}{*}{ Indicator description } & \multicolumn{3}{|c|}{$\begin{array}{l}\text { Parents visiting } \\
\text { a transmural nurse } \\
\text { clinic } \\
(\mathrm{n}=139)\end{array}$} & \multicolumn{3}{|c|}{$\begin{array}{c}\text { Parents visiting an } \\
\text { extramural nurse } \\
\text { clinic } \\
(\mathbf{n}=63)\end{array}$} \\
\hline & & $\mathbf{r}^{2}$ & $\mathbf{P}$ & $\mathbf{R}^{3}$ & $\mathbf{r}^{2}$ & $\mathbf{P}$ & $\mathbf{R}^{\mathbf{3}}$ \\
\hline \multicolumn{8}{|c|}{ Health professionals or health institutions should: } \\
\hline 1 & provide the necessary care & 4.5 & 4.7 & 1.1 & 4.8 & 4.7 & 1.0 \\
\hline 2 & $\begin{array}{l}\text { adapt care when necessary in } \\
\text { changing situations }\end{array}$ & 4.8 & 4.8 & 1.0 & 4.9 & 3.7 & 0.7 \\
\hline 3 & $\begin{array}{l}\text { provide care immediately during } \\
\text { emergencies }\end{array}$ & 4.9 & 4.9 & 1.0 & 4.9 & 5.0 & 1.0 \\
\hline 4 & keep to the time of appointment & 4.1 & 4.6 & 1.3 & 4.3 & 4.9 & 1.2 \\
\hline 5 & $\begin{array}{l}\text { not cancel an appointment without } \\
\text { reason }\end{array}$ & 4.3 & 4.9 & 1.5 & 4.1 & 5.0 & 1.8 \\
\hline 6 & be reachable by the telephone & 4.6 & 4.5 & 1.0 & 4.8 & 4.6 & 0.9 \\
\hline 7 & provide concurrent care & 4.9 & 4.8 & 1.0 & 4.9 & 4.8 & 1.0 \\
\hline 8 & cooperate with each other & 4.8 & 4.7 & 1.0 & 4.7 & 4.8 & 1.0 \\
\hline 9 & have a locum in case of absence & 4.6 & 2.8 & 0.6 & 4.6 & 3.7 & 0.7 \\
\hline 10 & $\begin{array}{l}\text { give sufficient information to a } \\
\text { substitute }\end{array}$ & 48 & & & & & \\
\hline 11 & give compatible advice & 4.4 & $\begin{array}{l}5.0 \\
4.5\end{array}$ & $\begin{array}{l}1.0 \\
1.2\end{array}$ & 4.0 & $\begin{array}{l}4.3 \\
4.8\end{array}$ & $1.6^{*}$ \\
\hline 12 & not provide care with too many & & & & & & \\
\hline & different care providers & 4.2 & 4.8 & 1.5 & 4.0 & 4.9 & 1.6 \\
\hline 13 & $\begin{array}{l}\text { refer me to another care provider } \\
\text { when necessary }\end{array}$ & 4.3 & 2.8 & 0.6 & 4.4 & 4.3 & $1.0^{*}$ \\
\hline 14 & give each other sufficient information & & & & & & \\
\hline & concerning patient's situation & 4.9 & 4.0 & 0.8 & 4.9 & 3.5 & 0.7 \\
\hline 15 & visit patients at home when necessary & 4.0 & 4.7 & 1.7 & 4.5 & 4.9 & 1.1 \\
\hline
\end{tabular}

1. Differences in ratio scores between the two groups were determined by ANCOVA. with statistical adjustment for the severity of the illness.

2. The final verston of the $\mathrm{gCC}$ does not contain importance indicators. Despite this, the authors chose to use importance scores because this gives the opportunity for giving practical advice to improve the continutty of care in transmural and extramural nurse clinics.

3. $R_{y}=P_{y} / I_{y}$. The ratio $(R)$ on a health service (j) by an fndividual patient (f) is equal to the mean (perceived) performance score (P) divided by the mean importance score (I).

$\cdot=\mathrm{p}<0.05$.

Table 2. Mean importance scores(l), mean performance scores $(P)$, mean ratio scores $(R)$, and statistical test 
results of the continuity indicators ${ }^{1}$

Parents' experiences relating to the continuity of care given at transmural and extramural nurse clinics can be deduced from the mean performance scores $(P)$ in Table 2. The performance of transmural nurse clinics was experienced as optimal regarding indicator 10, "give sufficient information to a substitute." Parents visiting an extramural nurse clinic scored indicator 3, "provide care immediately during emergencies," and 5, "not cancel an appointment without reason," as optimal. Negative experiences with transmural nurse clinics occurred on indicator 9, "have a locum in case of absence," and 13, "refer me to another care provider when necessary." Relatively poor experiences of extramural nurse clinics were reported for indicator 14, "give each other sufficient information concerning patient's situation."

The mean ratio scores show a positive score on most continuity indicators for both kinds of clinic. However, perceptions of parents visiting a transmural nurse clinic were less than optimal on continuity indicators 9 , "have a locum in case of absence," 13, "refer me to another care provider when necessary," and 14, "give each other sufficient information concerning patient's situation." These indicators had a mean ratio score less than 1.0. Less positive mean ratio scores in extramural nurse clinics were found for continuity indicators 2 , "adapt care when necessary in changing situations," 6 , "be reachable by telephone," 9 , "have a locum in case of absence," 10, Ogive sufficient information to a substitute," and 14, "give each other sufficient information concerning patient's situation."

Significant differences between transmural and extramural nurse clinics occurred on two continuity indicators. Table 2 shows that parents consulting an extramural nurse clinic experienced the compatibility of advice given by different health professionals more positively than the positive experience with this indicator had of parents visiting a transmural nurse clinic. This signific ant difference in parents' positive experiences has no relevance in relation to a future continuity improvement program.

Another significant difference between the two kinds of clinics related to indicator 13, "refer me to another care provider when necessary." Parents visiting extramural nurse clinics scored this continuity indicator as positive while parents visiting a transmural nurse clinic gave this indicator a mean ratio score below 1.0 , which indicates a negative perception.

\section{CONCLUSIONS AND DISCUSSION}

In the Netherlands and other European countries, nurse-run asthma clinics are used in order to face problems in the quality and continuity of care of asthmatics. 5,6,8,9 The content of such clinics consists mainly of giving patients information about their illness and supporting patients in dealing with their asthma. In the Netherlands, two types of clinics, "transmural" and "extramural" nurse clinics, are distinguished. "Extramural" nurse clinics are the responsibility of a home care organization alone while "transmural" nurse clinics are the joint responsibility of a hospital and home care organization.

In this study, parents were not assigned randomly to the two kinds of clinics distinguished by organizational structure. However, it appeared that the two groups did not differ on most background characteristics. There was a difference in the severity of children's asthma between the groups. This was taken into account in the statistic al analyses.

To a large extent, the organizational differences between the two kinds of nurse clinics do not influence asthmatic children's parents' experiences with the quality and continuity of the care provided. The absence of large differences can be a result of the fact that parents do not attach much importance to the organization of the care provided, but focus mainly on the content of the care process. Because transmural and extramural nurse clinics do not differ in this respect, it is not surprising that differences between the perceived quality and continuity of care in the two kinds of clinics did not occur.

A choice made in the design of this study concerns the six-week period between measuring parents' expectations and experiences. If this period were extended to six months, for instance, it is possible that other differences between the two groups would be found

In regard to the quality of care, no negative quality judgments were found in either kind of clinic. It therefore can be concluded that future quality improvement programs in transmural and extramural nurse clinics are not necessary. However, it is important to maintain today's positive quality judgments in quality assurance programs.

With respect to the continuity of care some aspects were shown to be relevant for improvement in Dutch transmural and extramural nurse clinics. Parents visiting transmural or extramural nurse clinics indicated that health professionals (such as specialist asthma nurses and pediatricians) do not always give each other sufficient information about a child's situation. Parents also indicated that in both transmural and extramural nurse clinics, a substitute specialist nurse was not always available in case of absence. Additionally, parents visiting a transmural nurse clinic had fewer positive experiences in the frequency with which they were referred by the specialist nurse to other care providers (such as a pediatrician) in cases where parents thought necessary. This result is 
incongruent with the goals of transmural nurse clinics in general. It is assumed that pediatricians and specialist nurses work closer in transmural nurse clinics and therefore will communicate more easily with each other than in the case of extramural nurse clinics. Parents who visited extramural nurse clinics noted fewer positive experiences regarding the way in which care was adapted in changing situations, the telephone access to the specialist nurses, and whether specialist nurses gave sufficient information to a substitute or other professionals. These subjects are areas for special attention in continuity of care improvement of extramural nurse clinics.

This article also gave insight into specialist asthma nurses' and pediatricians' perceptions about transmural and extramural nurse clinics. Both specialist asthma nurses and pediatricians participating in this study share the opinion that nurse clinics are a positive innovation. Patients get additional information at the clinics and nurses are more accessible for patients than other providers such as pediatricians. However, professionals involved in both kinds of clinics plan to deal with impeding factors in the clinics. It is hoped that through this process, the positive influences of transmural and extramural nurse clinics will be strengthened. It therefore is recommended that in the future, a referral system to clinics is considered before using clinics in daily nursing practice.

\section{REFERENCES}

1. P. Ludwig-Beymer et al. "Improving Care for Adults with Asthma across the Continuum," Journal of Nursing Care Quality 12, no. 6 (1998): 48-55. [Context Link]

2. A.J. Eastwood and T.A. Sheldon. "Organization of Asthma Care: What Difference Does It Make? A Systematic Review Of The Literature," Quality in Health Care 5, (1996): 134-143. [Context Link]

3. A. Nocon and T. Booth. "The Social Impact of Asthma," Family Practice 8, no. 1 (1990): 37-41. [Context Link]

4. C. van Campen et al. "Assessing Noninstitutionalized Asthma and COPD Patients' Priorities and Perceptions of Quality of Health Care: The Development of the QUOTE-CNSLD Instrument," Journal of Asthma 34, no. 6 (1997): 531-538. [Context Link]

5. I. Charlton et al. "An Evaluation of a Nurse-Run Asthma Clinic in General Practice Using an Attitudes and Morbidity Questionnaire," Family Practice 9, no. 2 (1992): 154-160. [Context Link]

6. K.P. Jones and M.A. Mullee. "Proactive, Nurse-Run Asthma Care in General Practice Reduces Asthma Morbidity: Scientific Fact or Medical Assumption," British Journal of General Practice 45, (1995): 497-499. [Context Link]

7. J. Droogan and K. Bannigan. "Organization of Asthma Care: What Difference Does It Make?" Nursing Times 93 , no. 34 (1997): 45-46. [Context Link]

8. G. Barnes and M.R. Partridge. "Community Asthma Clinics: 1993 Survey of Primary Care by the National Asthma Task Force," Quality in Health Care 3, (1994): 133-136. [Context Link]

9. D. Temmink et al. "Dutch Transmural Nurse Clinics for Chronic Patients: A Descriptive Study," In press. [Context Link]

10. A.F. Casparie et al. Vragenlijst Continuïteit van Zorg Vanuit Cliëntperspectief (VCC) Handleiding en Vragenlijsten (Questionnaire Continuity of Care from the Clients' Perspective (Utrecht/Amsterdam/Groningen: NIVEL, VU, RUG, 1998). [Context Link]

11. M.B. Miles and A.M. Huberman. Qualitative Data Analysis. An Sourcebook of New Methods (Beverly Hills: SAGE Publications, 1984). [Context Link]

12. M.B. Miles and A.M. Huberman. Qualitative Data Analysis. An Expanded Sourcebook. 2nd ed. (Newbury Park: SAGE Publications, 1994). [Context Link]

13. V. Peters et al. Kwalitatieve Analyse in de Praktijk en Handleiding bij Kwalitan (Qualitative Analyze in Practice and Manual for Kwalitan) SWI-reeks (Nijmegen: Katholieke Universiteit Nijmegen, 1989). [Context Link] 
IMAGE GALLERY

Select All

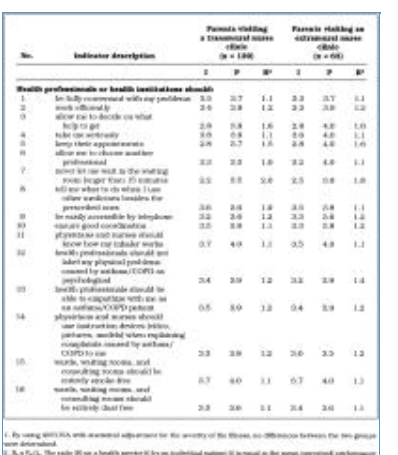

Table 1

Back to Top
可 Export Selected to PowerPoint

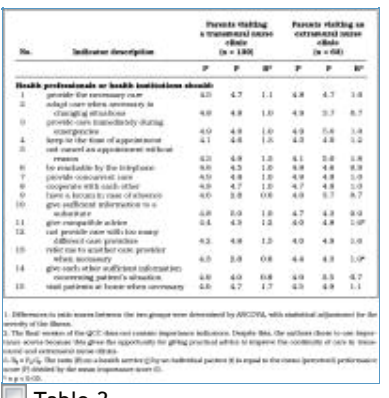

Table 2

Copyright (c) 2000-2013 Ovid Technologies, Inc.

Terms of Use | Support \& Training | About Us | Contact Us

Version: OvidSP_UI03.09.01.101, SourceID 58904 